\title{
One world one burn rehabilitation standard
}

\author{
M.A. Serghiou ${ }^{a, *}$, J. Niszczak ${ }^{b}$, I. Parry ${ }^{c}$, C.W.P. Li-Tsang ${ }^{d}$, \\ E. Van den Kerckhove ${ }^{e}$, S. Smailes ${ }^{f}$, D. Edgar ${ }^{g, h, i, j}$ \\ a Shriners Hospitals for Children, Galveston, TX 77550, USA \\ ${ }^{\mathrm{b}}$ Temple University Burn Center, Philadelphia, PA, USA \\ ' Shriners Hospitals for Children, Northern California, Sacramento, CA 95817, USA \\ d Department of Rehabilitation Science, The Hong Kong Polytechnic University, Hong Kong \\ ${ }^{\mathrm{e}} \mathrm{KU}$ Leuven, Department of Rehabilitation Sciences, Belgium \\ ${ }^{f}$ St. Andrews's Centre for Plastic Surgery and Burns Broomfield Hospital, Australia

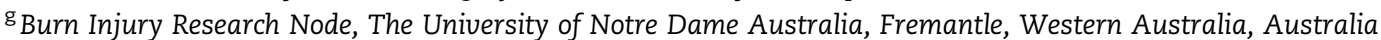 \\ ${ }^{\mathrm{h}}$ Fiona Stanley Hospital, Murdoch, Western Australia, Australia \\ ${ }^{\mathrm{i}}$ Fiona Wood Foundation, Murdoch, Western Australia, Australia \\ ${ }^{j}$ Burn Injury Research Unit, University of Western Australia, Crawley, Western Australia, Australia
}

\section{A R T I C L E I N F O}

Article history:

Accepted 4 April 2016

Keywords:

Burn

Rehabilitation

International

Standard of care

\begin{abstract}
A B S T R A C T
According to the World Health Organization (WHO) burns are a huge global health problem resulting in death and devastation to those who survive large burns as they are faced with significant functional limitations that prevent purposeful and productive living. Members of the International Society for Burn Injuries (ISBI) Rehabilitation Committee conducted a needs assessment survey in order to characterize how burn rehabilitation is implemented worldwide and how the international burn rehabilitation community can help improve burn rehabilitation in identified geographic locations which need assistance in rehabilitating burn survivors successfully. The results of this survey indicated that poor and in some cases resource limited environments (RLEs) around the world seem to lack the financial, educational and material resources to conduct burn rehabilitation successfully. It appears that there are vast discrepancies in the areas of education, training and capacity to conduct research to improve the care of burn survivors as evidenced by the variation in responses between the RLEs and developed countries around the globe. In some cases, the problem is not knowledge, skill and ability to practice burn rehabilitation, but rather having the resources to do so due to financial difficulties.
\end{abstract}

(C) 2016 Elsevier Ltd and ISBI. All rights reserved.

\section{Introduction}

According to the World Health Organization (WHO), over 265,000 people die worldwide each year as a result of a burn related accident [1]. Of these deaths, approximately $95 \%$ occur in resource limited environments (RLE's) and countries [2]. More significantly, people who survive serious burns are in the millions and are often faced with significant functional limitations that prevent purposeful and productive living.

\footnotetext{
* Corresponding author at: Shriners Hospitals for Children, Rehabilitation Services Department, 815 Market Street, Galveston, TX 77550, USA. Tel.: +1 4097706681 .

E-mail address: mserghiou@shrinenet.org (M.A. Serghiou). http://dx.doi.org/10.1016/j.burns.2016.04.002 0305-4179/@ 2016 Elsevier Ltd and ISBI. All rights reserved.
} 
Specifically, the WHO reports that burns account for 10 million disability adjusted life years (DALYs) lost globally each year. In 2004, eleven million non-fatal burns require hospitalization and/or some type of treatment [1]. Observational visits and experiences of the authors affirm that a disproportionate number of these burn survivors develop significant burn wound contractures and suffer other physical and psychological impairments that limit their function thus, negatively influencing their chance of full recovery and returning to productive living $[2,3]$.

Physical rehabilitation is a broad specialty and is essential in helping burn survivors recover from their injuries and restore their capacity for independence and gainful existence $[4,5]$. The goal of burn rehabilitation is to assist patients to achieve their maximum potential in physical function, cosmetic appearance and teach them to adapt where permanent functional loss is sustained and to return to their life roles and skills [5]. Additionally, rehabilitation specialists help in the community reintegration process of these survivors, focusing on recovery of quality of life and return to participation in all life roles and skills. Rehabilitation therapists around the world have similar goals in the rehabilitative process along the continuum of care however they go about achieving these goals in many different ways [2,6]. In the developed countries of the world, burn rehabilitation is often conducted at hospitals and other medical facilities equipped with modern equipment utilized by professionals who have access to greater resources, theoretically providing the greatest chance of success and best patient outcomes. In contrast, rehabilitation clinicians in RLEs may not be available as part of the multidisciplinary team, or if present have minimal resources and, or expertise to provide the basic and specific rehabilitation interventions [1]. That said, anecdotes abound to testify that clinicians in RLEs adapt to the surroundings well and with minimal decision making support and training promote a sustainable and acceptable level of rehabilitation. Technological advances and devices to improve function are rapidly expanding in their number, applicability and quality. Unfortunately, these adjunct solutions are often (too) expensive and not sustainable in the RLEs due to scalability and other challenges such as a lack of maintenance resources or programs, reliable electricity and marginal applicability in unforgiving climates. Rehabilitation specialists in RLEs are faced with further challenges such as having minimal or sporadic availability of resources to care for their patients and limited provision and access to knowledge, skills and expertise to help those who do survive serious burns [3,4]. Their goals in burn recovery are clear and their willingness and passion to accomplish them are admirable however they are hindered in their ability to respond due to challenges noted.

In recent years, medical institutions, foundations and NonGovernmental Organizations (NGOs) worldwide have been conducting health professional missions to various RLEs around the world to help in the care burn survivors [6]. These medical teams consist most commonly of surgeons and nurses who deliver and teach surgical interventions to treat patients and provide meaningful education on the overall care of the burn survivor. The lack of training and support for burn rehabilitation skills has been highlighted in these missions, and this is compounded by a lack of available therapists and rehabilitation professionals. The role burn rehabilitation clinicians fulfill worldwide has not previously been examined. In 2012, during the proceedings of the 16th Congress of the International Society for Burn Injuries (ISBI), the president of the society emphasized the need for ISBI to work in an organized fashion and in collaboration with WHO to decrease the incidence of burn mortality (and morbidity) worldwide through prevention campaigns and improve patient care focusing specifically in the developing countries [1,4]. The official theme of the 2012 ISBI Congress was "One World, One Standard of Burn Care" and focused on topics of education, prevention, clinical care and epidemiology of the burn. Through the continuous encouragement and support from the leadership of the ISBI, the society's Rehabilitation Committee began working on the "One World, One Rehabilitation Standard" project at the completion of the 2012 ISBI Congress. The aims of the project were to: (a) describe the state of burn rehabilitation and profile local rehabilitation providers around the globe, (b) document associated professional development and education opportunities, and (c) explore the reasons and limitations to provision of rehabilitation services and conducting research projects. A team of burn rehabilitation professionals, members of the ISBI Rehabilitation Committee, designed a needs assessment in the form of a survey with the hope of collecting information on how rehabilitation is conducted around the globe and to identify where and why rehabilitation is lacking in some countries in order to make recommendations to the international burn community regarding solutions to improve the status of burn patient rehabilitation pathways and clinician training programs worldwide.

\section{Methods}

A 28 question, burn rehabilitation specific survey (Appendix A), was developed by the members of the International Society for Burn Injuries (ISBI) Burn Rehabilitation Committee with input from external advisors. The survey was delivered via email, regular mail, in person and by phone to burn centers of member countries of the ISBI utilizing the burn center directory of the society. Further distribution of the survey occurred through the Burn Rehabilitation Committee member networks, with snowballing sampling of recipients to propagate the survey as far around the world as possible. The survey had two respondent invitation periods that occurred over a span of two years. After Phase One, a review of the respondent countries was completed, gaps were identified and Phase Two survey targeted distribution was designed and implemented. Additional international rehabilitation contacts were engaged within the Pan African Burn Association, as well as the American and European Burn Associations. The survey was translated by native medical professionals and made available in English, Spanish, French, German, Dutch and Chinese. Within the timeframes and scope of the study, back translation and adjustment for cultural differences was not feasible however the translation to the different languages was performed by medical translators in the countries (geographic areas) where the languages mentioned above are spoken. Questions included (a) demographics, (b) burn rehabilitation interventions (positioning, splinting, exercise, and scar management), (c) patient follow up, (d) 
rehabilitation specific continuing education opportunities, (e) physical agents used and ( $\mathrm{f}$ ) availability of rehabilitation specific material resources. Where applicable those who responded to the survey had the opportunity to choose more than one answer to a question and to include free text to expand their answers and provide additional insight into the specific local circumstances.

\subsection{Data analysis}

Data are presented in descriptive terms using MS Excel to summarize percentages and counts. Data was collated first by country then region and then (if available) burn facility or hospital that received burn patients where responses were received from multiple burn centers were collated and summarized by two senior authors to represent a unified report from each country taking into account the size of a country and the socioeconomic disparities in large countries of the world such as China, India and Mexico. In larger developed nations such as North America and Australia, responses were averaged according to the states or provinces within the country itself to better identify the representative response of the current level of skill across the entire country as well as to emphasize the short falls where comprehensive care may be less than optimal even when resource needs appear to be plentiful.

\section{Results}

Of the 195 independent countries of the world, 117 countries from 7 continents responded to the survey which roughly represents a $60 \%$ response rate covering a great deal of the world's geographical area. Phase One produced surveys from 72 countries. Phase Two afforded an expansion of the information from many of the previously surveyed countries but also included responses from an additional 45 countries with a greater proportion of the latter respondents from RLEs, due to the targeted nature of the second wave of survey distribution. Appendix B illustrates the survey responses from countries across all continents. Greater than a 50\% response rate was received from either burn centers or specialty hospitals across all regions except Africa (Fig. 1). Africa also had the smallest ratio of identified "burn centers" available in its countries per capita. North America and Australia had the greatest number of "burn centers" per capita and the highest response rates to the survey across both phases. In an effort to quantify and effectively weight the survey results (and to gather a better representative view of the global data), responses from multiple burn centers within the same state or province of individual counties were averaged and their details are represented as a percentage of all available burn centers within the entire country itself. As this was the first effort of its kind to capture data from all over the globe, in many of the middle income countries and RLEs, calculated assumption was taken by the authors in an attempt to accurately weigh the responses since in many of these regions, a well-defined burn rehabilitation p process has not been established. In addition, the authors further used their direct connections to sew up the loosely connected burn providers in many of the vast regions whom do not have an operational profile or operate under a full administrative hospital structure.

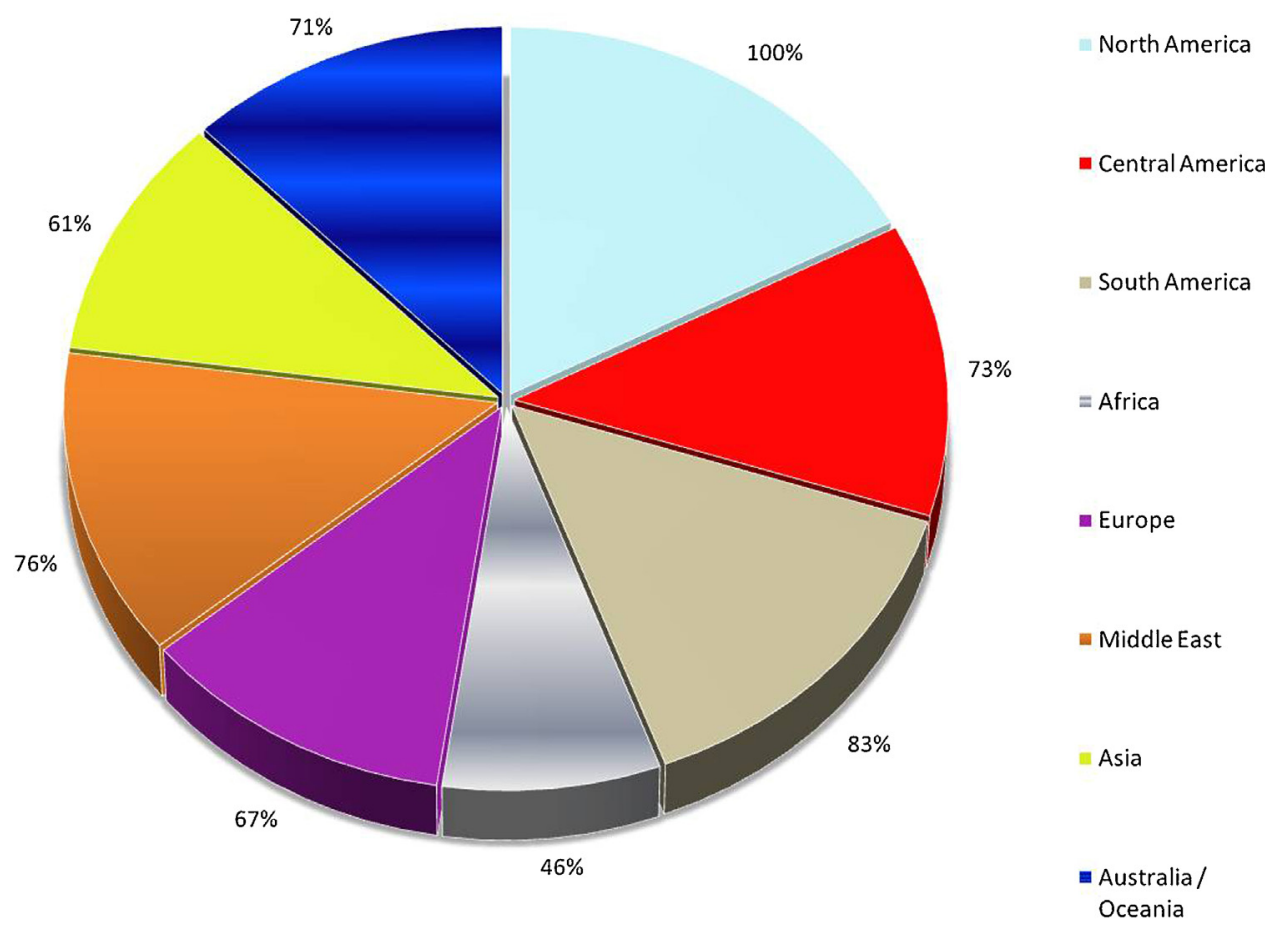

Fig. 1 - Survey responses across continents; the percentages are derived from the ratio of surveys sent to countries within a continent vs. the number of countries that responded to the survey. Even though multiple surveys may have been received from one country the percentages above are calculated based on the number of countries that responded to the survey (not the number of surveys received per country). 


\subsection{Demographics}

The majority of the respondents (64\%) reported that they work at either a "burn center" or "burn unit" within a hospital. Respondents included MDs or "chief surgeon" (43\%), Occupational Therapists (17\%), Physical Therapists (27\%) and Nurses (12\%). Other respondents included 2 program directors and 2 clinical psychologists. In some RLEs, the MD served as surgeon, nurse, therapist, psychologist and after-care coordinator. The majority of the respondents surveyed (71\%) reported at least Master Level education. The number of years of experience per respondents was highest in the 6-10 years category (30\%) followed closely by those individuals with greater than 16 years of burn care experience (37\%) (Fig. 2). Additional analysis showed that for many of the RLEs, staff retention correlated with training and support in the burn center, especially when additional training and or NGO visitations took place.

\subsection{Therapeutic interventions}

The therapeutic interventions most reportedly used in acute rehabilitation were positioning (82\%), splinting (81\%) and exercise (78\%) (Fig. 3). Clinicians in African countries reported significant challenges with burn rehabilitation interventions during the acute phase of care with only $27 \%$ of the countries reporting they position patients in the anti-deformity position and only $18 \%$ splint the burn patient. These countries report a lack of resources as well as lack of a specific rehabilitation programs (or clinicians), and education which may explain the limited intervention. Respondents reported using active

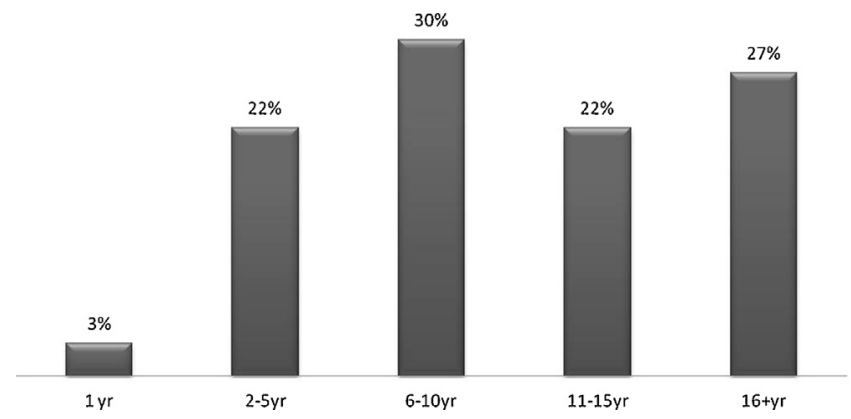

Fig. 2 - Average years working in burn care.

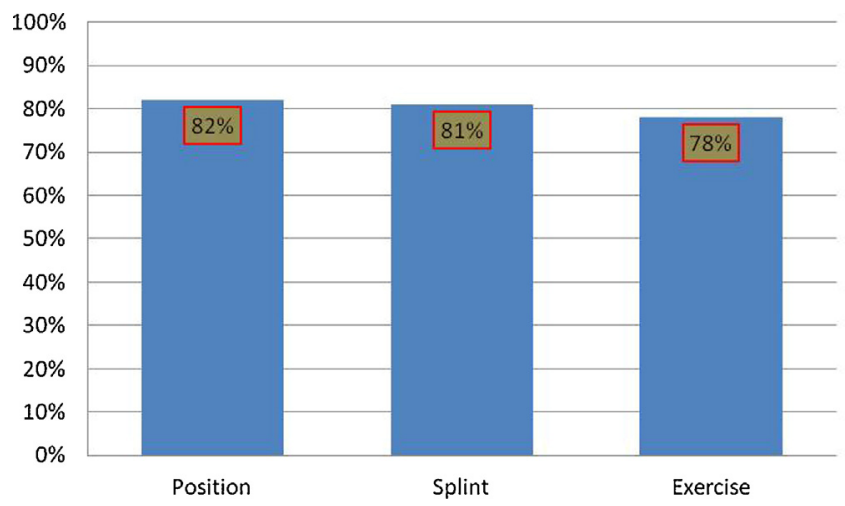

Fig. 3 - Therapeutic interventions most utilized in acute burn rehabilitation. movement and exercise twice as often as splinting and positioning during the acute or early intervention in burn rehabilitation. Simple manual exercise or mobility was used as prescribed "daily intervention" on the whole across all continents and countries. The most common types of exercise reported to mitigate the scar hypertrophy process and facilitate mobilization were a combination of AROM, AAROM and PROM (85\%). The data suggest that there are similar numbers of clinicians "using" and regularly "not using" other types of objective scar assessment tools. The most common instruments reportedly used were the modified Vancouver Scar Scale (MVSS) and goniometry. The use of standardized assessment is a growing area of interest in the burn rehabilitation literature and this was supported by the majority of survey responses.

\subsection{Scar management}

For scar management, the majority of respondents (73\%) utilize some type of pressure modality and the type and use corresponded directly to the monetary limitations and fiscal hospital constraints within each facility. Overwhelmingly, massage was the most common scar management modality and did not appear to be influenced by any economic or monetary constraints. In fact, massage was consistently mentioned as a treatment when other resources (in particular absence or limited pain medication) were limited.

\subsection{Physical agents}

The physical agent modalities most used included paraffin and moist heat. They were more routinely used than electrotherapy by a margin of slightly more than $2: 1$.

\subsection{Resource limitations}

Expected limitations to improving access to resources (money, resources and educational training) were reported consistently across all countries regardless of income level. African countries $(90 \%)$ reported lack of the basic resources needed to conduct simple burn rehabilitation tasks the most frequently followed by Central America (72\%).

\subsection{Rehabilitation specific continuing education}

Overall, the majority (93\%) of respondents identified the need for more training and collaboration with the NGO's and partners, mentioning onsite physical workshop and training missions were warranted and preferred. For the most part African countries have no rehabilitation continuing education opportunities and all survey respondents from this continent (100\%) expressed the need for rehabilitation specific continuing education and training.

\subsection{Rehabilitation pathways}

Crucially important to the long term efficacy of any burn rehabilitation program is the burn survivor's ability to return for follow up and aftercare visits [5]. Based upon the results of the survey, we have found that there is a uniform distribution of follow-up across all the countries and continents surveyed. 
Reviewing the data to look at the distribution of the responses, we found the higher the overall income, the higher the rate of return to follow up. Open ended responses revealed that, follow up was also influenced highly by additional societal implications and stigmas particularly on the continents of Africa and Asia. For example this is one statement - "To improve burn rehabilitation in my state access to education opportunities is vital. In addition, allocation of appropriate therapist time to cover patient numbers is required. The current part time allocation of staff is not meeting the needs of children and their families. Furthermore, if I am on leave there is no money within our departmental budget to provide locum cover as backfill. We need education, fulltime allocation of burn care caseload and leave cover." Overall, the majority (77\%) responded to this open ended question to provide specific data on the circumstances that need support. In regard to the data collected regarding out-patient follow up and clinic return, we found an inverse relationship between TBSA percentage and the consistency of follow up care - that is as the TBSA increases, the rate of follow up decreases and this trend persisted across all countries regardless of resource availability (Fig. 4). The majority of the respondents (82\%) surveyed reported that they did complete at least some follow up after discharge but the accuracy and the consistency decreased in parallel with the declining resource availability. In the developed nations the follow up was more standardized and routine and had more consistency in access across disciplines. In the RLE's, this pattern was much more diverse and poorly monitored. Often, the function of follow up diminished proportionally to the economic sustainability of both the facility itself and the individual that sustained the burn. Asian countries followed closely by Middle Eastern and Central American countries (in this order) indicated similar results as the nations from Africa. North American, Western European and South American countries (in this order) reported greater consistency of use of burn rehabilitation specific interventions, and indicated that there were frequent opportunities for rehabilitation continuing education and burn rehabilitation specific research. These results are not unexpected as material resources are more abundant in these areas of the world and structured, credentialed Physical and Occupational Therapy programs are more readily available in these countries.

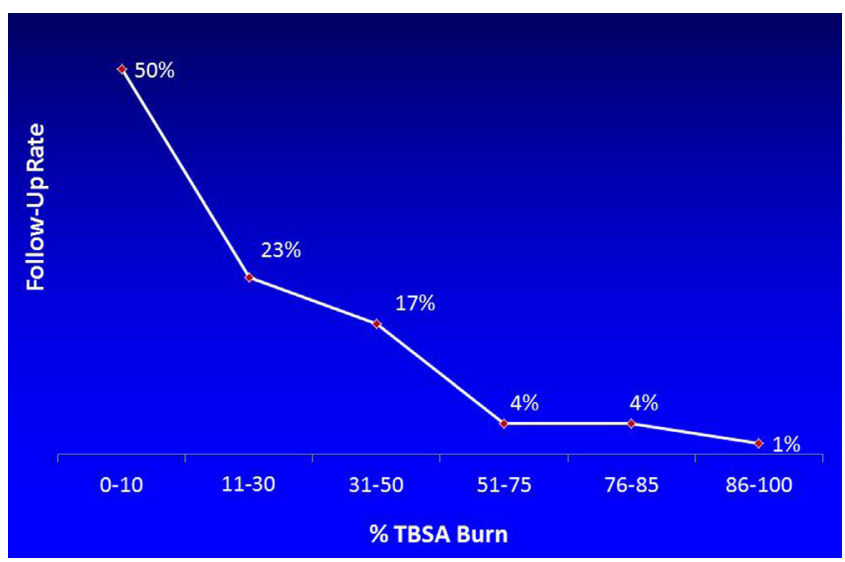

Fig. 4 - Outpatient follow up in relation to burn size.

\section{Discussion}

Based on the data collected from around the globe, significant disparities exist among countries in terms of both accesses to specialty trained clinicians who provide burn rehabilitation services and manage injury after the acute stage. This study clearly identified that burn patient access to rehabilitation services and training are lacking in RLE's. To address this mammoth challenge, and improve patient outcomes in any environment, we need to raise awareness of the benefits of minimizing variation to best practice through provision of burn care standards, and provide RLE clinicians with access to experienced trainers in burn rehabilitation. The goal of burn rehabilitation is universally - to provide maximal functional return of physical, social and emotional wellbeing [5,6]. It must be made clear that relative to other interventions by the burn team, rehabilitation is a low cost endeavor because significant improvements in patient outcomes are possible by 'doing the simple things well' through practical training and adaptive, innovative use of scant resources [7]. Despite this, we have confirmed that basic skills training and education of rehabilitation and techniques are severely lacking in the RLEs but also, rehabilitation specific training is not abundant in any environment outside undergraduate therapy curricula. Thus, rehabilitation interventions were shown to be, as may be expected, inconsistently applied and provided less often than in better resourced countries. Progress continues to be made via outreach education, and via NGOs and non-profit support but the ability to sustain baseline levels of rehabilitative interventions is plagued by the difficulties of establishing contact between appropriate clinicians and the pitfalls of lack of: resources; manpower to train and be trained; formal and observational training opportunities; and, funding. As an 'alltoo-common' example, charitable visits to countries in Africa in 2015 confirm the findings of the survey in terms of a total lack of burn rehabilitation and many other aspects of burn care. This problem appears to be multifactorial and is exacerbated by a lack of basic resources and education. Resources are scarce in many African countries as confirmed by the findings of the survey in that Africa has the least number of burn centers per capita. Thus, not only do clinicians have limited capacity to provide rehabilitation, but patients have extremely limited access to burn care. Often they travel many miles to reach a burn center or cannot, reportedly, attend at all for assistance. This is compounded by a lack of burn education and training programs for qualified staff at burn centers. Consequently, most burn patients in many African countries receive very limited inpatient and no followup burn therapy at all. Despite this, experience has demonstrated that therapists working in Africa are asking for support and, indeed, are very receptive to training and this provides a great opportunity to improve burn rehabilitation in the future through strategies discussed in this paper. All co-authors have similar personal anecdotes after visits in South America, Nepal and the Asian continent.

The goal of One World, One Burn Rehabilitation Standard of Care that was postulated at the ISBI meeting in 2012 in Scotland is beyond the reach for many of the countries surveyed in our study. The ISBI remains committed to 
establishing guidelines and training to approach a minimum standard of burn care (including rehabilitation) in all burn care settings around the world. The work ahead to achieve this goal is well underway, though will take time and commitment at all levels within the international burn care community. To improve the practical skills in burn rehabilitation, the strategy to achieve delivery of education and training in conjunction with the available burn care guidelines is far more challenging and will rely on many individual efforts. These efforts revolve around personal connection, which we believe is the fundamental core to success of the strategy to achieve the One World, One Standard of Burn Rehabilitation goal. The findings of this study prompt the ISBI Burn Rehabilitation Committee to commit to the development of the Burn Outreach and Rehabilitation Network (BORN), a private and secure personnel volunteer linkage system that aims to connect rehabilitation specialists around the world to collaborate in providing rehabilitation assistance (education, training, program development, etc.) to areas around the world where rehabilitation is needed the most. However, in moving forward our study suggests that the education and training effort would benefit from a more systematic approach, combined with an outcome monitoring framework, to ensure that the regions of greatest need are supported as a priority, tapping into the experience and capabilities of better resourced countries (burn rehabilitation teams). Further, readers are to be made aware of sentinel rehabilitation publications that have been circulated since the inception of this study. Each takes steps toward the provision of specific frameworks for applying knowledge and training in rehabilitation services. Parry and Esselman published Clinical Competencies for Rehabilitation Therapists. Their "burn rehabilitation therapist competency tool" (BRTCT) defines competency domains and provides for training locally available clinicians to provide safe levels of core rehabilitation interventions, traditionally delivered by physical and occupational therapists worldwide. The outline provided can be readily graduated to support basic training modules to support attainable burn rehabilitation goals [8]. Richard et al. in 2015 published the Hierarchical Decomposition of Burn Body Diagram Based on Cutaneous Functional Units and Its Utility. In his publication, Richard has postulated and demonstrated in clinical trials the use of Cutaneous Functional Units (CFU's) which allows more accurate prediction of burn scar contracture which encourages more efficient utilization of therapy resources [9]. Lastly, the Australian and New Zealand Burn Association Allied Health Group and the Joanna Briggs Institute, published the broad reaching resource: Burn Trauma Rehabilitation: Allied Health Practice Guidelines, Evidence based guidance for contemporary rehabilitation post-burn [10].

These publications, in light of our findings, further necessitate the need for development of global standard measures and consistent ways of thinking about outcomes as well as standards of practice regardless of economic access. Therapists need to work together internationally to create resources that are relevant and helpful to burn care clinicians in every country. An example of such resource recently released on the Journal of Burn Care and Research website standardizes scar massage procedures [11]. Moreover, there is clearly a need to raise the bar on global burn care in order to improve the outcomes in our individual rehabilitation clinics and hospitals in the developed countries [12,13]. If we look at the most relevant data related to contracture acuity after burn, we find that the rate of contracture is still highly prevalent. Thanks to advances in modern medicine in the last 50 years, survival rates of larger surface area burns have globally readily increased. The bar upon which burn care outcomes will be measured is no longer based on survival but firmly set as the return of function in recovery. Our global rehabilitation efforts need to be systematic and embrace the attainment of One World, One Burn Rehabilitation Standard now. The authors purport that the findings of this study may help guide, adapt and direct future ISBI/WHO/NGOs rehabilitation specific missions for training and education to specific areas of the world. These health care entities may be able to occasionally join forces and collaborate in delivering burn rehabilitation where it is greatly needed in the most efficient and meaningful ways [14].

\section{Study limitations}

This study was conducted by experienced rehabilitation practitioners from around the world who distributed the study via all known professional networks in an attempt to survey the worldwide burn clinician community. However, it is likely that these contacts were not all encompassing. Therefore, while attempting to be all inclusive, it is possible that responses are biased due to the lack of data available from regions not reached by the distribution strategy. For this, the authors apologize and hope that those who may feel that their voice was not heard will articulate their unique challenges in addition to those identified by our survey through Letters to the Editor submitted to this journal.

\section{Conclusion}

The survey indicate that resource limited countries seem to lack the financial, training and material resources to conduct burn rehabilitation consistently. This study indicated the need for worldwide access to: standardized clinical guidelines; linkage of experienced rehabilitation trainers with less experienced clinicians; development of accessible opportunities for rehabilitation education and training. In contrast, developing (middle Income) countries seem to have well-trained rehabilitation professionals who are able to successfully rehabilitate burn survivors however basic material resources in these countries are not plentiful $[13,15]$. In the developed countries, there are plenty of financial and material resources to successfully rehabilitate the burn survivor. Rehabilitation specialists are well trained to care for burn patients along the continuum of care and have the financial capability to conduct research to advance burn rehabilitation. Overall, regardless of the economic strata, burn rehabilitation with outcome focused data are needed and should be emphasized in order to elevate the level of rehabilitative care delivered to the burn survivor. It is the authors' hope that the data generated by this survey may be used by the international burn community to facilitate connecting rehabilitation specialists from around the world so that they can begin to collaborate to improve the care of burn survivors. 


\section{Authors' contributions}

All authors contributed to the conception and design of this study, data analysis and interpretation, preparation and verification of this final manuscript prior to submission for publication.

\section{Conflict of interest}

The authors have no conflicts of interest to declare in both the conduct of this project or preparation of this manuscript.

\section{Acknowledgements}

The authors wish to express their sincere gratitude to Ms. Elisabeth Greenfield, Administrative Director of the ISBI and Drs. Mackie, Gamelli and Ahuja, ISBI Presidents for their support and encouragement in carrying out this project. Special thanks to Ms. Victoria Aguilar-Ochoa for her administrative assistance in making this project possible.

Appendix A. Current State of Burn Rehab around the World (Survey)

Purpose: To generate a needs assessment for burn rehabilitation specialists around the world

Objective(s):

1) To determine the current educational level of burn therapists globally.

2) To determine resources availability within burn rehabilitation globally.

3) To connect burn rehabilitation specialists around the world and engage

in educational exchange collaboration in research and further improve

clinical practice.

1. Country of practice

2. Do you work in a burn center?
a) Yes
b) $\mathrm{No}$

3. What is your occupation?
a) OT
b) PT
c) Other

4. Do you treat adult or pediatric burns or both?
a) Adult
b) Pediatric
c) Both

5. How many years of burn rehab experience do you have?
a) 1
b) $1-5$
c) $6-10$
d) $11-15$
e) 16 or more

6. What degree have you obtained?
a) Bachelors of Science
b) Masters
c) Doctorate
d) Other

7. Do your burn patients have access to an Intensive Care Unit (ICU)?
a) Yes
b) No 
8. If you have answered yes in question 7, does your burn center have an ICU or are your patients managed in a general ICU outside the burn center?

a) ICU within the burn center

b) General ICU

9. What is your intervention with acute burns? Please circle all that apply.
a) Positioning
b) Splinting
c) Exercise
d) All of the above
e) Other

10. Do you have available resources to splint burn patients?

a) Yes

b) No

11. What type of material do you use for splinting/positioning? Please circle all that apply.
a) Thermoplastics
b) Plaster
c) Other (please list)

12. What mode of exercise do you apply while the patient is in the hospital? Please circle all that apply.
a) Active Range of Motion
b) Passive Range of Motion
c) Active Assistive Range of Motion
d) Stretching
e) Strengthening/ resistance
f) All of the above

13. How do you manage edema in the acute phase of recovery? Please circle all that apply.

a) Positioning

c) Other

14. Do you splint in the Operative Room (OR)?

a) Yes

b) No

15. What does your scar management program consist of? Please circle all that apply.

a) Elastic bandages

b) Pressure garments

c) Massage

d) Inserts

e) Other 
16. What type of garments do you use? Please circle all that apply.
a) Interim
b) Custom
c) Both
d) Other

17. What type of insert material do you use?
a) Foam
b) Silicone
c) Gel
d) Elastomer

18. What physical agent modality do you use for your patients? Please circle all that apply.
a) Hot patches
b) Paraffin wax
c) Other

19. What electrotherapy modality do you use for your patients? Please circle all that apply.
a) Ultrasound
b) TENS
c) Galvanic stimulation
d) Muscle stimulation
e) All of the above

20. Do you follow your patients in an outpatient basis?
a) Yes
b) No

21. In your case, what is the percentage of patient return to your outpatient clinic after discharge from the hospital? This question is intended to determine the patient "lost to follow up" rate for your burn center.
a) $0-10 \%$ return rate
b) $11-30 \%$ return rate
c) $31-50 \%$ return rate
d) $51-75 \%$ return rate
e) $76-85 \%$ return rate
f) $86-100 \%$ return rate

22. Is continuing education for burn rehabilitation available in your country?
a) Yes
b) No 
23. What are the limiting factors in providing basic burn rehabilitation? Please circle all that apply.
a) Money
b) Education
c) Resources
d) Skill
e) Other

24. Please indicate in a narrative form what is needed to improve burn rehabilitation for your country.

25. Are there any post-graduate study options or courses that relate to burn care or rehabilitation in you country?

26. In what ways could rehabilitation specialists better communicate and collaborate in the future? Please circle all that apply.

a) Continuing education

b) Educational exchange

c) Web based projects

d) Construction of website

e) Other 
Appendix B. Survey Responses across Continents by Country

North America

- United States, Canada, Mexico

Central America

- Bahamas, Barbados, Costa Rica, Cuba, Dominican Republic, El Salvador, Grenada, Guatemala, Haiti, Honduras, Jamaica, Nicaragua, Panama, Trinidad \& Tobago

South America

- Argentina, Bolivia, Brazil, Chile, Columbia, Ecuador, Paraguay, Peru, Uruguay,

Venezuela

Africa

- Algeria, Botswana, Cameroon, Chad, Congo, Egypt, Ethiopia, Ghana, Guinea, Ivory Coast, Kenya, Liberia, Malawi, Morocco, Mozambique, Nigeria, Senegal, Sierra Leone, South Africa, Tunisia, Uganda, Zimbabwe, Burkina Faso, Tanzania, Niger, Benin

Europe

- Austria, Azerbaijan, Armenia, Belarus, Belgium, Bulgaria, Croatia, Cyprus, Czech Republic, Denmark, Finland, France, Georgia, Germany Greece, Hungary, Ireland, Italy, Latvia, Macedonia, Monaco, Netherlands, Poland, Portugal, Spain, Sweden, Switzerland, Ukraine, United Kingdom

Middle East

- Afghanistan, Iran, Iraq, Israel, Jordan, Kuwait, Lebanon, Palestine, Qatar, Saudi

Arabia, Turkey, UAE, Yemen

Asia

- China, Japan, South Korea, India, Taiwan, Russia, Sri Lanka, Philippines, Singapore,

Malaysia, Vietnam, Thailand

Australia/Oceania

- Australia, Fiji, Kiribati, Marshall Islands, New Zealand, Palau, Samoa, Solomon

Islands, Tonga, Vanuatu

Australia/Oceania - sent survey to 14 countries; 10 countries responded $=71 \%$ Middle East - sent survey to 17 countries; 13 countries responded $=76 \%$

Asia - sent survey to 19 countries; 12 countries responded $=61 \%$

Africa - sent survey to 56 countries; 26 countries responded $=46 \%$

Europe - sent survey to 43 countries; 29 countries responded $=67 \%$

South America - sent survey to 12 countries; 10 countries responded $=83 \%$

Central America - sent survey to 19 countries; 14 countries responded $=73 \%$

North America - sent survey to 3 countries; 3 countries responded $=100 \%$ 


\section{R E F E R E N C E S}

[1] WHO Fact Sheet No 365; May 2012 and April 2014, http:// www.who.int/mediacentre/factsheets/fs365/en/.

[2] Peck M, Molnar J, Swart D. A global plan for burn prevention and care. Bull World Health Organ 2009;87:802-3.

[3] World Health Organization. The injury chart book: a graphical overview of the global burden of injuries. Geneva: Department of Injuries and Violence Prevention Noncommunicable Diseases and Mental Health Cluster/ World Health Organization; 2002.

[4] Leblebici B, Adam M, Bağiş S, Tarim AM, Noyan T, Akman MN, et al. Quality of life after burn injury: the impact of joint contracture. J Burn Care Res 2006;27:864-8.

[5] Richard RL, Hedman TL, Quick CD, Barillo DJ, Cancio LC, Renz EM, et al. A clarion to recommit and reaffirm burn rehabilitation. J Burn Care Res 2008;29:425-32.

[6] Mock C, Peck M, Peden M, Krug E, editors. A WHO plan for burn prevention and care. Geneva, Switzerland: World Health Organization; 2008.

[7] Richard R, Baryza MJ, Carr JA, Dewey WS, Dougherty ME, Forbes-Duchart L, et al. Burn rehabilitation and research: proceedings of a consensus summit. J Burn Care Res 2009;30:543-73.

[8] Parry I, Essleman P. Clinical competencies for rehabilitation therapists. J Burn Care Res 2011;32(4):1-10.
[9] Richard R, Jones J, Parshley P. Hierarchical decomposition of burn body diagram based on cutaneous functional units and its utility. J Burn Care Res 2015;36:33-43.

[10] Edgar D. Burn trauma rehabilitation: allied health practice guidelines. Philadelphia, PA: Lippincott Williams \& Wilkins; 2014.

[11] Parry I, Icaza I, Poveda SV, Flores Abrego AE, Hernández Barrantes EA, Garita EB, et al. Defining massage techniques used for burn scars. J Burn Care Res 2016. Retrieved from: http://journals.lww.com/burncareresearch/pages/ videogallery.aspx?videold=5\&autoPlay=false.

[12] Asuquo ME, Ekpo R, Ngim O. A prospective study of burns trauma in children in the University of Calabar Teaching Hospital, Calabar, south-south Nigeria. Burns 2009; 35:433-6.

[13] Chen J, Li-Tsang CW, Yan H, Liang G, Tan J, Yang S, et al. A survey on the current status of burn rehabilitation services in China. Burns 2013;39(2):269-78.

[14] Ozgediz D, Dunbar P, Mock C, Cherion M, Rogers Jr SO, Riviello R, et al. Bridging the gap between public health and surgery: access to surgical care in low- and middle-income countries. Bull Am Coll Surg 2009;94:14-20.

[15] Ottomann C, Kleinschmidt A, Gohlke G, Biedermann I, Hartmann B. Development and restructuring of a burn centre in an emerging nation, based on the example of Kyrgyzstan. Burns 2009;35:437-42. 